Social Indicators Research

\title{
Are people who participate in cultural activities more satisfied with life? --Manuscript Draft--
}

\begin{tabular}{|c|c|}
\hline Manuscript Number: & SOCI-D-14-00045R1 \\
\hline Full Title: & Are people who participate in cultural activities more satisfied with life? \\
\hline Article Type: & Original Research \\
\hline Keywords: & $\begin{array}{l}\text { Life satisfaction; Subjective Wellbeing; Quality of life; leisure; cultural activities; } \\
\text { heritage recreation }\end{array}$ \\
\hline Corresponding Author's Institution: & University of Glasgow \\
\hline \multirow[t]{2}{*}{ Order of Authors: } & Jennifer Lee Brown, Ph.D. \\
\hline & Ronald MacDonald, Ph.D. \\
\hline Response to Reviewers: & $\begin{array}{l}\text { Responses to reviewer's comments: } \\
\text { "We recommend to remove the table } 2 \text { (ordinal regression...)" } \\
\mathrm{R}=\text { this table has been removed. } \\
\text { "we suggest to combine Appendix } 1 \text { and Appendix } 2 \text { in } \\
\text { a single table with multiple columns" } \\
\mathrm{R}=\text { since Appendix } 2 \text { was included only so the insignificant associations and table } 2 \\
\text { could be better } \\
\text { understood, this has been deleted altogether and appendix } 1 \text { has been left unchanged. } \\
\text { "in fact, if the association is not significant should not be commented on" } \\
\mathrm{R}=\text { we agree in not presenting the specific data for } \\
\text { not significant associations (i.e. table } 2 \text { ) but we } \\
\text { disagree about not commenting on it. It is our point of view that an insignificant } \\
\text { association is worth } \\
\text { commenting on if, as in the present case, a significant association is expected. We } \\
\text { have come across } \\
\text { a recently published paper in Social Indicators Research that reports the same lack of } \\
\text { association }\end{array}$ \\
\hline
\end{tabular}


(i.e. Agyar, 2014). To explain this we have added a paragraph in page 6 which includes 3 new

references (i.e. Agyar, 2014; Russell, 1987 and Rag

heb and Griffith, 1982).

"Page 3: delete the sentence "Analyses were completed using SPSS 19" $\mathrm{R}=$ this sentence has been deleted 
Jennifer L. Brown ${ }^{1}$, Ronald MacDonald ${ }^{1}$ and Richard Mitchell ${ }^{2}$

${ }^{1}$ Adam Smith Business School, University of Glasgow, Glasgow, G12 8QQ, Scotland, UK

${ }^{2}$ Centre for Research on Environment, Society and Health, Institute of Health and Wellbeing, University of Glasgow, G12 8QQ, Scotland, UK

Corresponding author: jennifer.brown@glasgow.ac.uk, tel: +44 (0) 138256 8791, fax: +44(0) 1413304939 


\section{Introduction}

The definition of life satisfaction and other related terms, such as Quality of life (QOL) and Subjective wellbeing (SWB), has been the subject of continuous debate. There are no universal definitions for these terms and a discussion of definitions is beyond the scope of this paper (a good review of definitions is presented in Galloway 2006). We share the view of QOL as a multi-dimensional concept which comprises objective and subjective aspects (Felce 1997; Anderson et al. 1999; Galloway 2005). Within the field of happiness economics SWB is often equated to life satisfaction (Christoph and Noll 2003). Others suggest that SWB should comprise people's longer-term cognitive evaluations of their lives (satisfaction) as well as short-term emotional or affective expressions of mood (happiness) (Helliwell and Putnam 2004; Vitters $\varnothing$ 2004; Fleche et al. 2012). In this paper life satisfaction is used as a proxy for SWB and considered as a component of QOL.

The influence of various aspects of life on wellbeing, in particular, household income, employment, health and social connections has been extensively researched (Anderson et al. 2009; Fleche et al. 2012). Other aspects, such as leisure in general, and participation in sports and culture in particular, have been assumed to increase subjective wellbeing despite little empirical evidence to support this view (Bell 2006). Leisure in relation to subjective wellbeing is particularly important because it is more under personal control than other sources of life satisfaction (Hills and Argylle 1998). In a public consultation carried out by Oxfam, access to arts, culture, hobbies and leisure activities emerged unprompted as an important "sub-domain" of wellbeing and indeed seen as a flourishing aspect (Walker et al. 2012). Research on leisure and wellbeing tends to concentrate in the area of physical activity, in general or carried out in outdoor environments, and its association with psychological wellbeing (Dowall et al. 1988; Foong 1992; Bodin and Hartig 2003; Wendel-Vos et al. 2004; Pretty et al. 2005; Pretty et al. 2007; Hug et al. 2009; Thompson Coon et al. 2011; Mitchell 2012). However, not many studies have compared different types of leisure activities, including arts and culture, in relation to their contribution to life satisfaction. Some exceptions include Lloyd and Auld (2002) and, in the UK, Hills and Argyle (1998), Matrix, 2010 and Leadbetter and O'Connor (2013).

Lloyd and Auld (2002) examined the importance of both place and person-centred leisure attributes in predicting QOL. They found that frequency of engagement in social leisure activities and satisfaction with the psychological benefits derived from the experience were stronger correlates of QOL than place-centred attributes, such as use and satisfaction with leisure resources. Hills and Argyle (1998) made a comparative examination of four leisure activities in terms of the positive states arising from participation, their relationship with happiness and the influence of personality traits in the selection of activities. Matrix (2010) looked at the impacts of participation in the arts and sport on wellbeing and reported a positive impact on life satisfaction. Leadbetter and O'Connor (2013) examined the relationship between health and life satisfaction with participation in culture and sport. They reported an independent and significant association between good health and high life satisfaction with participation.

Some of the limitations of these studies relate to the restricted number of leisure activities considered. For example, Hills and Argyle (1998) used four leisure activities; Matrix (2010) considered only three, sports in general, going to the cinema and going to concerts. Also, the small number and selection process of participants make the results in Hills and Argyle and in Lloyd and Auld not generalizable. The only study at the population 
level which considers a wide number of leisure activities is that by Leadbetter and O'Connor. However, although they recognize in their study that employment is related to wellbeing, they did not include it as a control variable. Furthermore, they did not take into account the frequency of leisure participation or the number of activities engaged with in relation to life satisfaction.

Our study aims to address the limitations described above by using a large survey dataset to provide generalizable answers to the following research questions: do people who participate in sports and cultural leisure activities have higher life satisfaction than people who do not participate in these activities? And if this is true, do different types of activity have the same influence on life satisfaction? Does satisfaction depend on the frequency of participation or the number of activities engaged in?

\section{Methods}

The data used in this study come from Wave 2 of the Understanding Society Survey, also known as the United Kingdom Household Longitudinal Study (UKHLS) (University of Essex). The UKHLS captures important information every year about the social and economic circumstances and attitudes of approximately 40,000 people living in UK households (McFall 2012). The survey began with a representative probability sample of households, details of sampling design can be found in Lynn (2009). Most of the data collection was conducted face-to-face, via Computer Aided Personal Interview (CAPI), by trained interviewers. There were additional self-completion instruments for youth and adults. For the purpose of this study the analysis consisted of a crosssectional study of adults (respondents aged over 16) who completed the individual questionnaire of Wave 2, collected between January 2010 and January 2012. Only Wave 2 was used because Wave 1 did not carry the relevant items. The sample size for statistical analysis was of 32,707 individuals after the appropriate weight and filters were applied. Data were weighted to adjust for unequal selection probabilities, differential non-response and potential sampling error. In line with previous research using UKHLS data, negative household income values, those equal to 0 and those on the top and bottom $1 \%$ of positive income values were excluded from the analysis (Berthoud 2011).

The survey asks about participation in 78 leisure activities (39 cultural and 39 sports activities). To simplify the analysis, cultural activities were grouped into seven themed categories (Appendix 1). Sports are already grouped in the survey as moderate and mild intensity. Frequency of participation is also captured for art activities, art events, heritage and museum activities, and mild and moderate intensity sports. The adult self-completion questionnaire of the UKHLS asks respondents to report their level of satisfaction with life overall using a 7point Likert scale (from completely dissatisfied to completely satisfied). This life satisfaction variable was not normally distributed and cannot be treated as linear in a regression analysis. We therefore propose using an ordinal regression initially to assess the independent relationship between participation in each of the leisure group of activities and life satisfaction score. The link function used in the model was complementary log-log, as it is recommended when higher categories of the dependent variable are more probable and when the test of proportional odds or "parallel lines" is not met (ReStore 2013). The assumption of proportional odds states that the effects of any explanatory variables are consistent or proportional across the threshold categories and is the key assumption in ordinal regression analysis. However, the ordinal regression did not meet the assumption even after the complementary log-log function was used. A simple approach to analyse ordinal data with non- 
proportional odds is to dichotomize the ordinal response variable by means of several cut-off points and use separate binary logistic regression models for each dichotomized response (Bender and Grouven 1998). For subsequent analysis, therefore, the life satisfaction dependent variable was dichotomised into two cut-off points: level 7 and level 6 or above. This allows the comparison of respondents who said they are completely satisfied with life and the rest of respondents, and the combination of this group with those who are mostly satisfied against the rest of respondents.

Four covariates were controlled for in the regressions: gender, age, equivalised household income and occupation. These variables were selected based on both a literature review of factors influencing life satisfaction (e.g. Lucas et al. 2004; Boyce et al. 2012; Daraei and Mohajery 2013) and exploratory bi-variate analysis of the data which confirmed their association with life satisfaction in the UKHLS dataset. The modelling aimed to identify the unique (net) contribution of each group of leisure activities to overall life satisfaction after control for the covariates. Since all leisure activities were entered into the model simultaneously, the association between participating in a specific group of leisure activities and life satisfaction was adjusted for participation in all other activities as well.

The influence of frequency of participation in leisure activities on life satisfaction was explored by repeating the ordinal regression with the frequency variables in place of the "yes/no" participation variables. The influence of the number of leisure activities practiced in a year and life satisfaction was explored through linear regressions. The variable for the number of leisure activities carried out was obtained by adding all the leisure categories in which the respondents answered "yes".

\section{Results}

The mean number of leisure activities carried out by respondents in the 12 months previous to the interview was 9, with a standard deviation of 6.9. Figure 1 shows the popularity of each leisure category based on the percentage of respondents reporting having practiced at least one activity within the group in the 12 months previous to the interview. Reading hobbies was the most popular leisure group of activities with $74 \%$ of respondents reporting having participated in at least one activity from this group in the 12 months previous to the interview. The second most popular group of activities was moderate intensity sports, reported by $64 \%$ of respondents. Within this group, swimming/diving was the most practiced sport, reported by $34 \%$ of all respondents. Activities grouped under the themes "heritage visits" and "popular entertainment" were both reported by $63 \%$ of respondents. However, the most practiced activities within these groups, going to the cinema and visiting a city or town with historic interest, were reported by more people than swimming/diving (54\% and $44 \%$, respectively).

Fig. 1 Reported participation in categories of leisure activity in the 12 months previous to interview 
Figure 2 shows the distribution of responses to the overall life satisfaction question. The mode for life satisfaction as a whole was 6 , which means the most reported answer from the 7-point Likert scale was "mostly satisfied". About $15 \%$ of respondents reported a dissatisfaction category (completely, mostly or somewhat) and $76 \%$ stated they were satisfied (completely, mostly or somewhat).

Fig. 2 Frequency of response of life satisfaction categories

Table 1 summarizes the results of the ordinal regression aimed at assessing the independent association between various leisure categories and life satisfaction. The cumulative odds ratio (OR) shows that participants of the leisure categories Moderate intensity sports, Heritage hobbies, Mild intensity sports and Active-creative were more likely to report high life satisfaction levels compared to non-participants of these activities. Participants of Reading and Sedentary creative hobbies were less likely to report high life satisfaction scores than nonparticipants of these activities. The association of the categories Popular entertainment, Theatre hobbies and Museum/galleries with life satisfaction was not statistically significant.

The results of the binary logistic regressions show that the cumulative OR for reading (0.92) underestimates the reduction in likelihood of reporting level 7 of life satisfaction associated with reading hobbies. However, when level 6 and 7 are combined the association between reading hobbies and life satisfaction is not significant. Participation in moderate intensity sports and heritage hobbies was not associated with the highest level of life satisfaction. The cumulative OR for moderate intensity sports (1.09) in this case underestimates the representation of participants in higher levels of life satisfaction. For example, the odds for participants of moderate intensity sports being mostly satisfied or above (level 6+) are 1.23 times greater than the odds for nonparticipants, or in other words, people who participated in moderate intensity sports were $23 \%$ more likely to report high life satisfaction than non-participants. Similarly the odds for participants of heritage hobbies being mostly satisfied or above are 1.25 times greater than the odds of non-participants. The odds of mild intensity sports are very similar at this level at 1.21. Active-creative activities follow in general the same pattern, although the influence on life satisfaction is less marked than for sports and heritage hobbies. The odds for participants of active-creative activities being in level 7 are 1.17 times that of non-participants.

Table 1

The association between life satisfaction and the frequency of participation in leisure activities was not significant. However, the results of a linear regression point to higher life satisfaction levels when the number of activities practised increases. The standardised Beta coefficient for the number of activities indicates that for every increase in the number of leisure activities practised life satisfaction increases by $0.144(\beta=0.144$, $\mathrm{p}<0.001)$. 


\section{Discussion}

Our analyses show an independent positive association of participation in sport (moderate and mild intensity), heritage and active-creative leisure activities and life satisfaction and a negative association between participation in reading hobbies and sedentary-creative activities and life satisfaction. The leisure categories popular entertainment, theatre hobbies and museum/galleries were not statistically significant in their association with life satisfaction.

Two arguments can be given to explain the association between the types of leisure activities and life satisfaction and they are: $i$ ) the positive association of the categories sport, heritage and active-creative might reflect positive effects on health related to the physical activity involved in these leisure categories, and ii) the increase in life satisfaction reflects the social interactions generally involved in these activities.

Physical activity has been reported to have a positive effect on health, both physical (Hills and Argyle 1998; Brown et al. 2000; Wendel-Vos et al. 2004) and mental (Dowall et al. 1988; Foong 1992; Bodin and Hartig 2003; Wendel-Vos et al. 2004). Of the activities positively associated with higher life satisfaction, sports and active-creative (dancing being the main activity in this group) are obviously associated with physical activity. Heritage activities may compare with mild intensity sports in the amount of physical activity involved since these activities usually involve walking. Additionally, some of the heritage activities included in the category involve the outdoors which might act in combination with physical activity to improve mental health and, indirectly, life satisfaction (Bodin and Hartig 2003; Pretty et al. 2005; Pretty et al. 2007; Thompson Coo et al. 2011; Mitchell 2012).

Social interaction in itself has been recognised as an important contributor to happiness and wellbeing (Foong 1992; Auld and Case 1997; Diener and Seligman 2002; Fleche 2012). Many leisure activities have been reported to stimulate or promote social interaction, in particular sport activities (Foong 1992; Hills and Argyle 1998). Reading and activities included in the sedentary-creative category such as playing music and painting are generally done in isolation. Other activities which were not significant such as going to the cinema and the theatre, may involve carrying out the activity in company but this does not necessarily involve interaction. Other explanations for the association of sports, heritage and active-creative activities with higher life satisfaction may be a sense of achievement in doing these activities and, in the case of heritage, a sense of place and identity and their influence in increasing self-esteem (Campbell 1981; Diener and Diener 1995; Diener et al. 1985; Uchida et al. 2004).

Although popular entertainment, theatre hobbies and museum/galleries were not significantly associated with increased life satisfaction, this does not necessarily mean that they do not contribute to wellbeing. These activities, together with the reading and sedentary-creative groups, might have a positive effect in the affective aspect of SWB (mood, happiness) which was not taken into account in this analysis. There is more than one positive emotion associated with leisure and different types of leisure can produce different positive effects (Hills and Argyle 1998). For example, in other studies museums have been suggested to have a restorative effect and promote relaxation (Packer 2008), reduce anxiety (Binnie 2010), increase attention focus, promote a sense of community (Thompson et al. 2011) and to be associated with increased happiness and self-reported health 
(Fujiwara 2013; Leadbetter and O’Connor 2013). In contrast to our results, Leadbetter and O’Connor (2013) report a positive and significant association of attending museums, the cinema and dance performances with high life satisfaction. However, the results are not comparable to ours due to differences in the geographical area studied, scale of measurements and methods used.

A surprising outcome in the results is the lack of a significant association between life satisfaction and frequency of participation in leisure activities, as is often reported (e.g. Ragheb and Griffith 1982; Lloyd and Auld 2002). To our knowledge only two studies have reported this outcome before (Russell 1987; Agyar 2014). Russell (1987) suggested that the value of an activity may be determined more by the enjoyment derived from it than by the frequency of engagement. This and other hypotheses related to the levels of enjoyment derived by different leisure activities are suggested as areas to explore in future research.

It is important to highlight that the significant associations observed are not indicative of causation. Given the wide variety of leisure activities available, which ones are selected are determined by personal choice. People with higher levels of life satisfaction might tend to choose leisure pursuits that are more active and involve social interaction. Choices and the degree of happiness and satisfaction experienced with particular leisure activities and life in general might be influenced more by individual personality differences than by objective conditions (Felce and Perry 1995; Hills and Argyle 1998) and by personal values and aspirations (Felce and Perry 1996; Schalock 1996; Bell 2006).

In our study, the socio-economic and leisure variables included in the analysis explain a low proportion of the variability in the outcome (pseudo $\mathrm{R}^{2} 4.5 \%$ for the cumulative model). Personality has been considered a stronger and more consistent predictor of high life satisfaction (Wood et al. 2008; Boyce et al. 2013). Despite the low between-person variance in life satisfaction explained by socio-economic factors compared to personality, these are typically the focus of SWB research due to the belief that they change whereas personality does not. This view has been recently challenged by Boyce et al. (2013) based on a longitudinal study on personality change and life satisfaction. Regardless of whether personality changes over time or not, if it is a strong predictor of life satisfaction it should be included in wellbeing studies as a control variable. However, the major population surveys in the UK do not include personality measures. The availability of personality measurements would serve not only to control for this factor but also to understand the influence of personality in lifestyle choices such as leisure pursuits.

Large surveys, such as Understanding Society, provide the opportunity of establishing associations of various aspects of life with life satisfaction that can be generalizable at the population level. The main limitation of our study is that is cross-sectional due to the unavailability of leisure participation information in previous waves of the survey. Longitudinal studies are needed to identify possible causal relationships and the direction of the relation between specific leisure activities and life satisfaction, and to establish if long term participation is required. The nature of the associations can further be explored by including the types of positive emotions associated with individual leisure activities and personality aspects.

The importance of sports on wellbeing has long been recognized and it is high in the policy agenda, whereas other leisure activities such as heritage recreation have not been given the same importance. The results of this 
study show that the association of heritage leisure with life satisfaction is comparable to that of sports, and that these associations are independent of income and occupation, two strong correlates to life satisfaction (Anderson et al. 2009). In the face of economic change it would seem that an important way of improving social wellbeing and quality of life would be to create opportunities for engaging in a number of leisure activities, specifically those that are active and promote social interaction. Heritage recreation can provide these opportunities while being an alternative for people who do not like or cannot participate in sports. Policy makers and institutions in charge of providing heritage recreation should consider subjective wellbeing measures, such as life satisfaction, in the evaluation of their services.

\section{Conclusions}

In this paper we have used data from Wave 2 of the Understanding Society Survey to estimate the association of type, number and frequency of participation in leisure activities and life satisfaction, a component of quality of life. Our study demonstrates an independent and positive association of participation in sport (moderate and mild intensity), heritage and active-creative leisure activities and life satisfaction and a negative association between participation in reading hobbies and sedentary-creative activities and life satisfaction. The leisure categories popular entertainment, theatre hobbies and museum/galleries were not statistically significant in their association with life satisfaction.

The results showed that the association of heritage leisure with life satisfaction is comparable to that of sports, and that these associations are independent of gender, age, income and occupation. Two arguments were proposed to explain the association between the types of leisure activities and life satisfaction: $i$ ) the positive association of the categories sport, heritage and active-creative on health related to the physical activity involved in these leisure categories, and ii) the social interaction generally involved in these activities. Other aspects such as sense of achievement, sense of place and self-esteem may also explain these associations.

The results of this study have implications for policy makers and leisure services providers, in particular those associated with heritage recreation. Subjective wellbeing measures, such as life satisfaction and not economic measures alone should be considered in the evaluation of services. The promotion of heritage recreation and other activities which are active and promote social interaction should be considered in programmes aimed at improving the quality of life.

\section{Acknowledgements}

We are grateful to Henk Berits of the National Trust for Scotland for his advice and encouragement. 


\section{References}

Agyar, E. (2014) Contribution of perceived freedom and leisure satisfaction to life satisfaction in a sample of Turkish women. Social Indicators Research, 116, 1-15.

Anderson, R., Mikulić, B., Vermeylen, G., Lyly-Yrjanainen, M. \& Zigante, V. (2009) Second European quality of life survey overview. European Foundation for the Improvement of Living and Working Conditions, Luxembourg.

Auld, C. \& Case, A. (1997) Social exchange processes in leisure and non-leisure settings: A review and exploratory investigation. Journal of Leisure Research, 29, 183-200.

Bell, D. (2006) Annex 1: Review of research into subjective well-being and its relation to sport and culture. In: Galloway, S., Bell, D., Hamilton, C. \& Scullion, A. C. (Eds.) Quality of life and well-being: measuring the benefits of culture and sport literature review and thinkpiece. Series: Education (Scotland. Social Research). Scottish Government, Edinburgh.

Bender, R. \& Grouven, U. (1998) Using binary logistic regression models for ordinal data with non-proportional odds. Journal of Clinical Epidemiology, 51 (10) 809-816.

Berthoud, R. (2011) Income and other measures of material well-being. In: McFall, S. L. \& Garrington, C. (Eds.) Early findings from the first wave of the UK's household longitudinal study. Colchester: Institute for Social and Economic Research, University of Essex.

Binnie, J. (2010) Does viewing art in the museum reduce anxiety and improve wellbeing? Museums and Social Issues, 5 (2), 191-201.

Bodin, M. \& Hartig, T. (2003) Does the outdoor environment matter for psychological restoration gained through running? Psychology of Sport and Exercise, 4, 141-153.

Boyce, C. J., Wood, A. M. \& Powdthavee, N. (2013) Is personality fixed? Personality changes as much as "variable" economic factors and more strongly predicts changes to life satisfaction. Social Indicators Research, $111,287-305$.

Brown, W.J., Mishra, G., Lee, C. \& Bauman, A. (2000) Leisure time physical activity in Australian women: Relationship with well being and symptoms. Research Quarterly for Exercise and Sport, 71(3), 206-216.

Campbell, A. (1981) The sense of well-being in America. McGraw-Hill, New York.

Christoph, B. \& Noll, H. (2003) Subjective Well-Being in the European Union during the 90s. Social Indicators Research, 64 (3), 521-546.

Daraei, M. \& Mohajery, A. (2013) The impact of socioeconomic status on life satisfaction. Social Indicators Research, 112 (1), 69-81.

Diener, E. \& Diener, M. (1995) Cross cultural correlates of life satisfaction and self-esteem, Journal of Personality and Social Psychology, 68, 653-663.

Diener, E., Emmons, R. A., Larsen, R. J. \& Griffin, S. (1985) The satisfaction with life scale, Journal of Personality Assessment, 49, 71-75.

Diener, E. \& Seligman, M. E. P. (2002) Very happy people. Psychological Science 13, 81-84.

Dowall, J., Bolter, C., Flett, R. \& Kammann, R. (1988) Psychological well-being and its relationship to fitness and activity levels. Journal of Human Movement Studies, 14, 39-45.

Felce, D. (1997) Defining and Applying the Concept of Quality of Life. Journal of Intellectual Disability Research, 41 (2), 126-135. 
Felce, D. \& Perry, J. (1995) Quality of Life: Its Definition and Measurement. Research in Developmental Disabilities, 16 (1), 51-74.

Felce, D. \& Perry, J. (1996) Assessment of Quality of Life. In: Schalock, R. L. (Ed.) Quality of Life. Volume 1, Conceptualisation and Measurement, Washington: American Association on Mental Retardation.

Fleche, S., Smith, C. \& Sorsa, P. (2012) Exploring determinants of subjective wellbeing in OECD countries: evidence from the World Value Survey. OECD Statistics Working Papers, 2012/01, OECD Publishing. http://dx.doi.org/10.1787/5k9ffc6p1rvb-en

Foong, A. (1992) Physical exercise/sports and biopsychosocial well-being. Journal of the Royal Society of Health 112, 227-230.

Fujiwara, D. (2013) Museums and happiness: the value of participating in museums and the arts. The Happy Museum.

Galloway, S. (2006) Quality of life and well-being measuring the benefits of culture and sport. A literature review. In: Galloway, S., Bell, D., Hamilton, C. and Scullion, A. C. (Eds.) Quality of life and well-being: measuring the benefits of culture and sport literature review and thinkpiece. Series: Education (Scotland. Social Research). Scottish Government, Edinburgh.

Helliwell, J. F. \& Putnam, R. D. (2004) The Social Context of Well-Being. Philosophical Transactions of the Royal Society (London) Series B, Vol. 359, No. 1435-1446.

Hills, P. \& Argyle, M. (1998) Positive moods derived from leisure and their relationship to happiness and personality. Personality and individual differences, 25, 523-535.

Hug, S., Hartig, T., Hansmann, R., Seeland, K. \& Hornung, R. (2009) Restorative qualities of indoor and outdoor exercise settings as predictors of exercise frequency. Health and Place, 15, 971-980.

Leadbetter, C. \& O’Connor, N. (2013) Healthy attendance? The impact of cultural engagement and sports participation on health and satisfaction with life in Scotland. Scottish Government Social Research.

Lloyd, K. M. \& Auld, C. J. (2002) The role of leisure in determining quality of life: issues of content and measurement. Social Indicators Research, 57 (1), 43-71.

Lucas, R. E., Clark, A. E., Georgellis, Y. \& Diener, E. (2004) Unemployment alters the set point for life satisfaction. Psychological Science, 15 (1), 8-13.

Lynn, P. (2009) Sample design for Understanding Society. Understanding Society Working Paper 2009-01, University of Essex.

Matrix (2010) Understanding the drivers, impact and value of engagement in culture and sport. Culture and Sport Evidence (CASE) Paper.

McFall, S. L. (Ed.) (2012). Understanding Society -UK Household Longitudinal Study: Wave 1-2, 2009-2011, User Manual. Colchester: University of Essex

Mitchell, R. (2013) Is Physical Activity in Natural Environments Better for Mental Health than Physical Activity in Other Environments? Social Science and Medicine, 91, 130-134.

Packer, J. (2008) Beyond learning exploring visitors' perceptions of the value and benefits of museum experiences. Curator 2008, 51 (1), 33-54.

Pretty, J., Peacock, J., Hine, R., Sellens, M., South, N. \& Griffin, M. (2007) Green exercise in the UK countryside: effects on health and psychological well-being, and implications for policy and planning. Journal of Environmental Planning and Management, 50, 211-231. 
Pretty, J., Peacock, J., Sellens, M. \& Griffin, M. (2005) The mental and physical health outcomes of green exercise. International Journal of Environmental Health Research, 15, 319-337.

Ragheb, M. G. \& Griffith, C. A. (1982) The contribution of leisure participation and leisure satisfaction to life satisfaction of older persons. Journal of Leisure Research, 14 (4), 295-306.

ReStore (2013) University of Southampton: http://www.restore.ac.uk/srme/www/fac/soc/wie/researchnew/srme/index.html. Accessed 26 April 2013.

Russell, R. V. (1987) The importance of recreation satisfaction and activity participation to the life satisfaction of age-segregated retirees. Journal of Leisure Research, 19 (4), 273-283.

Schalock, R. L (1996) Reconsidering the Conceptualisation and Measurement of Quality of Life. In: Schalock, R. L. (Ed) Quality of Life, Vol. 1. Conceptualization and Measurement, Washington: American Association on Mental Retardation.

Thompson, S., Aked, J., McKenzie, B., Wood, C., Davies, M. \& Butler, T. (2011) The happy museum: a tale of how it could turn out all right. The Happy Museum.

Thompson Coon, J., Boddy, K., Stein, K., Whear, R., Barton, J. \& Depledge, M. H. (2011) Does participating in physical activity in outdoor natural environments have a greater effect on physical and mental wellbeing than physical activity indoors? A systematic review. Environmental Science and Technology, 45, 1761-1772.

Uchida, Y., Norasakkunkit, V. \& Kitayama, S. (2004) Cultural constructions of happiness: theory and empirical evidence. Journal of Happiness Studies, 5, 223-239.

University of Essex. Institute for Social and Economic Research and National Centre for Social Research, Understanding Society: Waves 1-2, 2009-2011 [computer file]. 4th Edition. Colchester, Essex: UK Data Archive [distributor], December 2012. SN: 6614. http://dx.doi.org/10.5255/UKDA-SN-6614-4.

Vittersø, J. (2004) Subjective Well-Being Versus Self-Actualization: Using the Flow-Simplex to Promote a Conceptual Clarification of Subjective Quality of Life. Social Indicators Research, 65 (3), 299-332.

Walker, P., Michaelson, J., Straus, K. \& Trebeck, K. (2012) Oxfam Humankind Index for Scotland Background. Methodology, consultation and report. Oxfam Research Report.

Wendel-Vos, G. C. W., Schuit, A. J., Tijhuis, M. A. R. \& Kromhout, D. (2004) Leisure time physical activity and health-related quality of life: cross-sectional and longitudinal associations. Quality of Life Research, 13, pp. 667-677.

Wood, A. M., Joseph, S., and Maltby, J. (2008). Gratitude uniquely predicts satisfaction with life: Incremental validity above the domains and facets of the five factor model. Personality and Individual Differences, 45, 4954. 


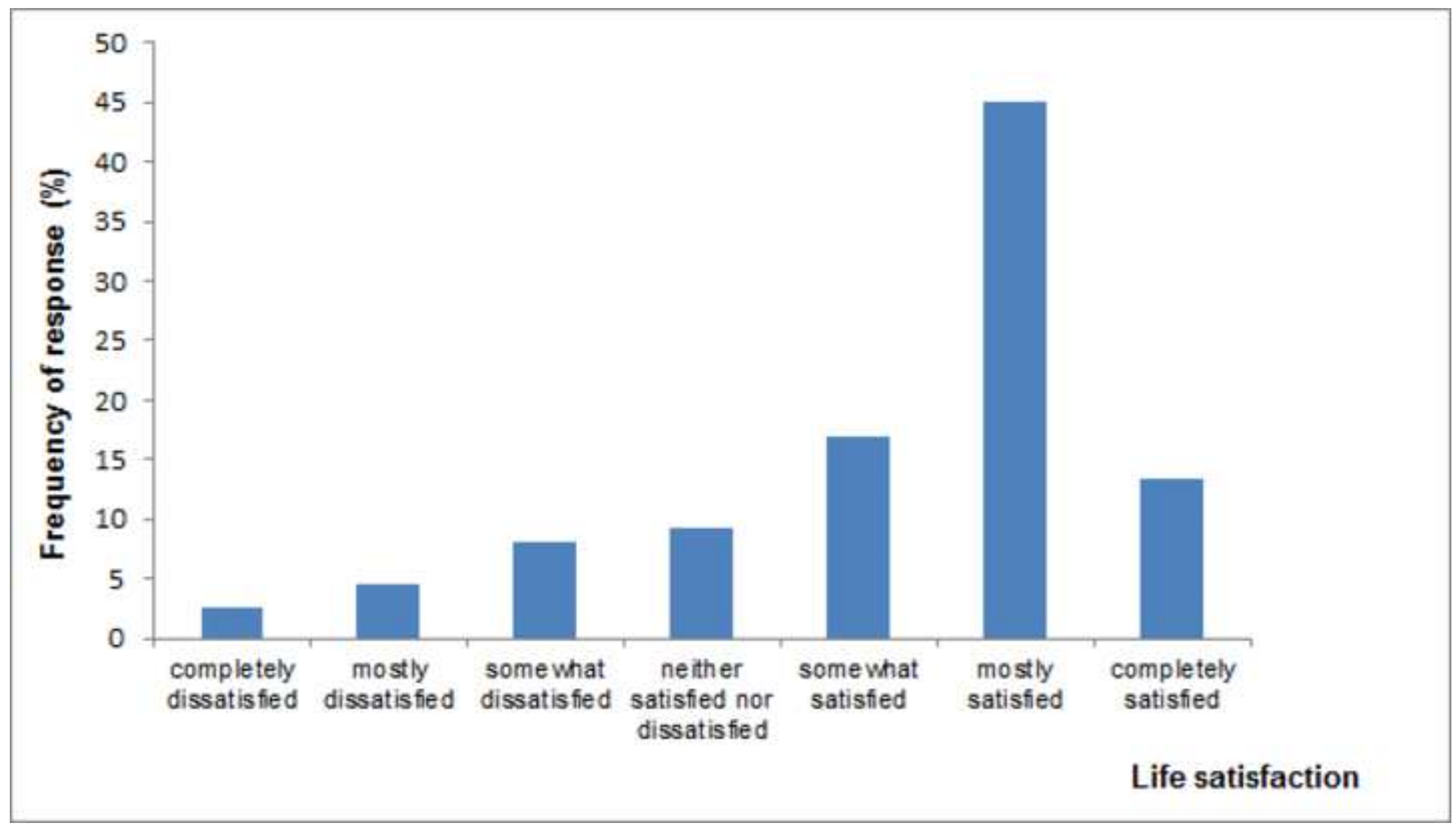


Click here to download Table: Table-1.docx

Table 1 Independent association between leisure categories and odds of high life satisfaction score

\begin{tabular}{|c|c|c|c|c|c|}
\hline & Odds ratio & & & & \\
\hline $\begin{array}{l}\text { Leisure } \\
\text { category }\end{array}$ & Cumulative $^{\mathrm{a}}$ & $\begin{array}{l}\text { Level } \\
7+b\end{array}$ & $\begin{array}{l}\text { Level } \\
6+b\end{array}$ & $\mathbf{S E}^{\mathbf{c}}$ & $95 \% \mathrm{CI}^{\mathrm{c}}$ \\
\hline $\begin{array}{l}\text { Reading } \\
\text { hobbies }\end{array}$ & $0.92 * * *$ & $0.79 * * *$ & 0.96 & 0.017 & 0.037 to 0.106 \\
\hline $\begin{array}{l}\text { Moderate } \\
\text { intensity } \\
\text { sports }\end{array}$ & $1.09 * * *$ & 1.08 & $1.23 * * *$ & 0.016 & 0.056 to 0.119 \\
\hline $\begin{array}{l}\text { Heritage } \\
\text { hobbies }\end{array}$ & $1.06 * * *$ & 0.99 & $1.25 * * *$ & 0.016 & 0.025 to 0.087 \\
\hline $\begin{array}{l}\text { Popular } \\
\text { entertainment }\end{array}$ & 1.01 & - & - & 0.016 & $\begin{array}{ll}-0.020 & \text { to } \\
0.044 & \end{array}$ \\
\hline $\begin{array}{l}\text { Mild intensity } \\
\text { sports }\end{array}$ & $1.08 * * *$ & $1.08 *$ & $1.21 * * *$ & 0.015 & 0.046 to 0.105 \\
\hline $\begin{array}{l}\text { Theatre } \\
\text { hobbies }\end{array}$ & 0.99 & - & - & 0.015 & $\begin{array}{ll}-0.039 & \text { to } \\
0.020 & \end{array}$ \\
\hline $\begin{array}{l}\text { Sedentary } \\
\text { creative }\end{array}$ & $0.97 *$ & 0.97 & $0.93 * *$ & 0.014 & $\begin{array}{lll}-0.059 & \text { to } & - \\
0.005 & & \end{array}$ \\
\hline $\begin{array}{l}\text { Museum/ } \\
\text { galleries }\end{array}$ & 0.97 & - & - & 0.015 & $\begin{array}{ll}-0.058 & \text { to } \\
0.002 & \end{array}$ \\
\hline $\begin{array}{l}\text { Active } \\
\text { creative }\end{array}$ & $1.07 * * *$ & $1.17 * * *$ & $1.11 * *$ & 0.017 & 0.037 to 0.106 \\
\hline $\begin{array}{l}\text { pseudo } \quad \mathrm{R}^{2} \\
\text { (Nagelkerke) }\end{array}$ & $4.5 \%$ & $4.6 \%$ & $7.9 \%$ & & \\
\hline
\end{tabular}


Appendix 1

Click here to download Attachment to Manuscript: Appendix 1.docx 